\title{
Understanding the Role of Crystallographic Shear Planes on the Electrochemical Behavior of Niobium Oxyfluorides
}

\author{
Nicholas H. Bashian, ${ }^{\dagger}$ Molleigh B. Preefer,,$\ddagger$ JoAnna Milam-Guerrero, ${ }^{\dagger}$ Joshua J. Zak, $₫$ \\ Charlotte Sendi, ${ }^{\dagger}$ Suha Ahsan, ${ }^{\dagger}$ Rebecca Vincent,${ }^{\ddagger}$ Ralf Haiges, ${ }^{\dagger}$ Kimberly A. See, ${ }^{\top}$ Ram \\ Seshadri, ${ }^{\ddagger}$ and Brent C. Melot ${ }^{*, \dagger}$ \\ $\dagger$ Department of Chemistry, University of Southern California, Los Angeles, CA 90089, USA \\ $\ddagger$ Materials Research Laboratory, UCSB, Santa Barbara, CA USA \\ IDivision of Chemistry and Chemical Engineering, California Institute of Technology, Pasadena, \\ California 91125, United States \\ E-mail: melot@usc.edu
}


Rietveld Refinement High resolution X-ray diffraction patterns of the as-synthesized $\mathrm{NbO}_{2} \mathrm{~F}$ and $\mathrm{Nb}_{3} \mathrm{O}_{7} \mathrm{~F}$ were collected at 11-BM, APS. The resultant patterns were refined against known structures to ensure phase purity of the materials. Relevant results are listed in Table T1.

Table T1: Results of the Rietveld refinement of pristine $\mathrm{NbO}_{2} \mathrm{~F}$ and $\mathrm{Nb}_{3} \mathrm{O}_{7} \mathrm{~F}$ against the synchrotron powder diffraction data. Note that in $\mathrm{NbO}_{2} \mathrm{~F}$, the $\mathrm{Nb}, \mathrm{O}$, and $\mathrm{F}$ all sit at fixed special positions.

\begin{tabular}{lcc}
\hline \hline Parameter & $\mathrm{NbO}_{2} \mathrm{~F}$ & $\mathrm{Nb}_{3} \mathrm{O}_{7} \mathrm{~F}$ \\
\hline \hline$a$ & $3.905(1)$ & $20.676(9)$ \\
$b$ & - & $3.834(1)$ \\
$c$ & - & $3.927(3)$ \\
Nb position & $(0,0,0)$ & $(0,0,0)$ \\
Nb2 position & - & $(0.183,0,0)$ \\
O position & $(0.5,0,0)$ & $0.5,0,0)$ \\
O2 position & - & $(0,0,0.5)$ \\
O3 position & - & $(0.097,0,0)$ \\
O4 position & - & $(0.706,0,0)$ \\
O5 position & - & $(0.190,0,0.5)$ \\
F position & $(0.5,0,0)$ & $(0.5,0,0)$ \\
F2 position & - & $(0,0,0.5)$ \\
F3 position & - & $(0.097,0,0)$ \\
F4 position & - & $(0.706,0,0)$ \\
F5 position & - & $(0.190,0,0.5)$ \\
$R_{\text {Bragg }}$ & 3.82 & 4.68 \\
\hline
\end{tabular}


Raman Mode Assignments Assignments of Raman modes of spectra displayed in the main text Figure 7.

Table T2: Vibrational mode assignments of the Raman spectrum of $\mathrm{NbO}_{2} \mathrm{~F}$ with descriptions

\begin{tabular}{cccc}
\hline \hline $\begin{array}{c}\text { Assignment } \\
\text { from ref 1-3 } \mathbf{1 - 3}^{\mathbf{1 - 3}}\end{array}$ & \multicolumn{2}{c}{ Raman shift $\left.\mathbf{( c m}^{-1}\right)$} & Mode description \\
Literature & Measured & \\
\hline \hline- & 196 & 193 & metal ions inside octahedron \\
- & 358 & 350 & $\mathrm{Nb}(\mathrm{O} / \mathrm{F})_{6}$ vibration \\
$\nu$ & 620 & 620 & $\mathrm{Nb}-\mathrm{F}-\mathrm{Nb}$ stretch or distorted Nb-O-Nb stretch \\
$\nu_{s}$ & 703 & 703 & $\mathrm{Nb}-\mathrm{O}$ stretch, Nb-O-Nb stretch \\
$\nu_{s}$ & 893 & 870 & $\mathrm{Nb}=\mathrm{O}$ terminal stretch \\
\hline
\end{tabular}

Table T3: Vibrational mode assignments of the Raman spectrum of $\mathrm{Nb}_{3} \mathrm{O}_{7} \mathrm{~F}$ with descriptions

\begin{tabular}{cccc}
\hline \hline $\begin{array}{c}\text { Assignment } \\
\text { from ref } \mathbf{3 , 4}^{\mathbf{3 , 4} 4}\end{array}$ & \multicolumn{2}{c}{ Raman shift $\left.\mathbf{( c m}^{-1}\right)$} & Mode description \\
Literature & Measured & \\
\hline \hline- & 90 & 89 & $\mathrm{NbF}_{6}$-related vibration \\
$\tau$ & 131 & 128 & $\mathrm{NbF}_{6}$-related vibration \\
$\delta_{s}$ & 248 & 254 & $\mathrm{O}=\mathrm{Nb}=\mathrm{O}$ twist \\
- & 299 & 291 & Nb-O-Nb bend \\
$\nu_{s}$ & 639 & 629 & Nb-O stretch in corner-sharing octahedra \\
$\nu_{s}$ & 692 & 675 & $\mathrm{NbO}_{6}$ symmetric stretch \\
& 993 & 984 & $\mathrm{Nb}=\mathrm{O}$ terminal stretch \\
\hline
\end{tabular}


Galvanostatic Cycling of $\mathbf{N b O}_{2} \mathbf{F}$ Galvanostatic cycling of $\mathrm{NbO}_{2} \mathrm{~F}$ in the voltage range of $1.0-1.5 \mathrm{~V}$ was seen to lead to poor reversibility due to irreversible reduction to $\mathrm{Nb}^{3+}$, as shown in Figure S1. By calculating the derivative of capacity with respect to voltage, as shown in the inset of Figure S1, it is possible to identify two distinct regions of redox with the first region from $1.5-2.0 \mathrm{~V}$ and the second from $1.0-1.5 \mathrm{~V}$.

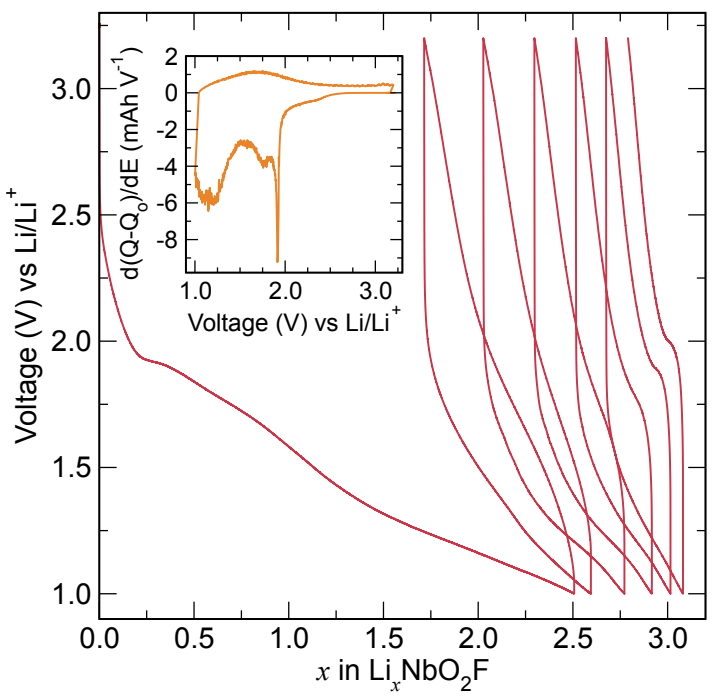

Figure S1: Galvanostatic cycling of $\mathrm{Li}_{x} \mathrm{NbO}_{2} \mathrm{~F}$ in the voltage window of $1.0-3.2 \mathrm{~V}$ shows poor reversibility. The inset displays a derivative of capacity with respect to voltage of the first cycle.

Galvanostatic Cycling of $\mathrm{Nb}_{3} \mathbf{O}_{7} \mathbf{F} \quad$ Cycling of $\mathrm{Nb}_{3} \mathrm{O}_{7} \mathrm{~F}$ with a voltage range of $1.0-3.2 \mathrm{~V}$ shows the differences between the first cycles and subsequent cycles. Figure S2 shows two distinct plateaus on discharge, with the insertion of three units of $\mathrm{Li}^{+}$. Upon initial charge, a dip in voltage is seen at $2.5 \mathrm{~V}$. Further cycling shows smooth, featureless curves.

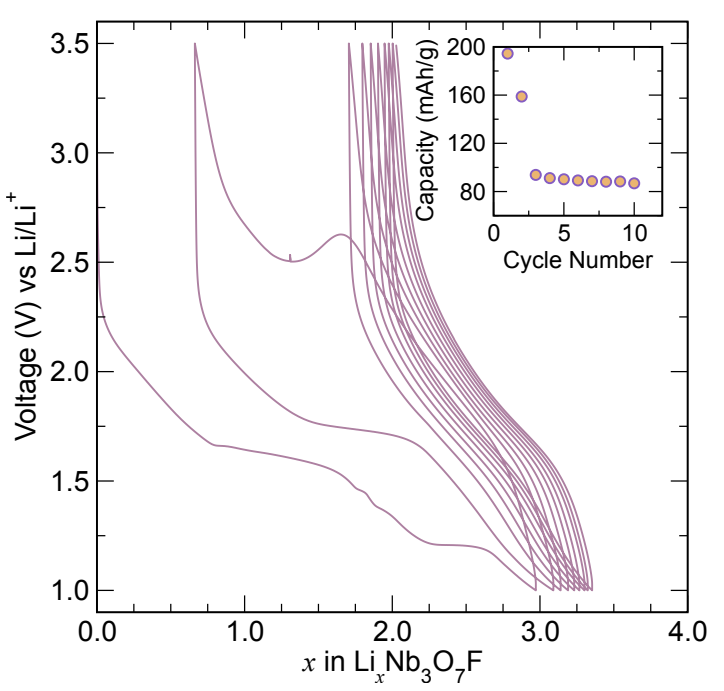

Figure S2: Galvanostatic cycling of $\mathrm{Li}_{x} \mathrm{Nb}_{3} \mathrm{O}_{7} \mathrm{~F}$ over the voltage range of $1.0-3.2 \mathrm{~V}$ shows a large irreversible initial capacity followed by cycling with a smooth voltage curve. 
Cyclic Voltammetry of $\mathrm{NbO}_{2} \mathbf{F}$ Cyclic voltammetry of $\mathrm{NbO}_{2} \mathrm{~F}$ with a voltage window of $1.0-3.2 \mathrm{~V}$ exhibits a broad oxidative peak due to deep reduction. The broad peaks are seen on both initial and subsequent cycles.

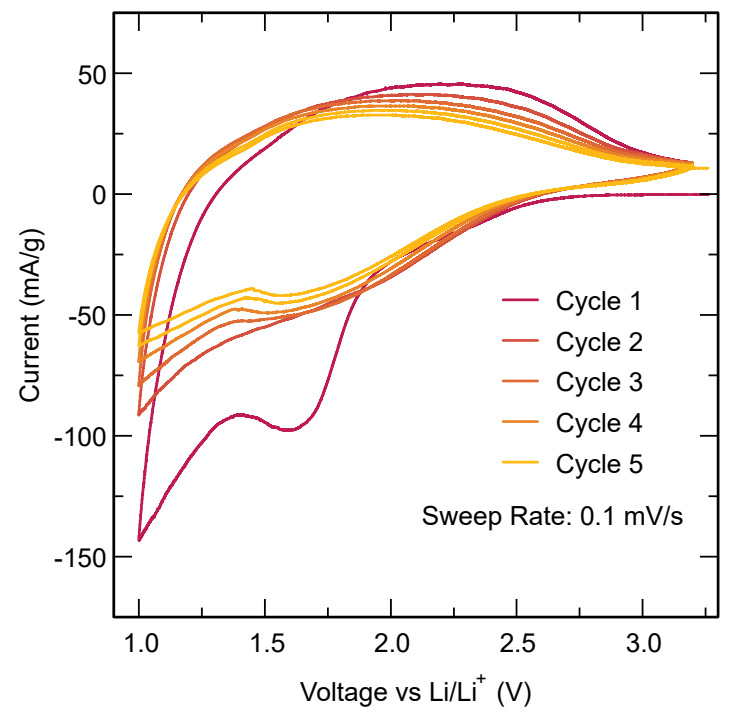

Figure S3: Cyclic voltammetry of $\mathrm{vNbO}_{2} \mathrm{~F}$ with a voltage window of $1.0-3.2 \mathrm{~V}$ demonstrates broad oxidative peaks.

Cyclic Voltammetry of $\mathrm{Nb}_{3} \mathrm{O}_{7} \mathbf{F}$ Cyclic voltammetry of $\mathrm{Nb}_{3} \mathrm{O}_{7} \mathrm{~F}$ with a voltage window of $1.0-3.2 \mathrm{~V}$ shows an irreversible peak at $2.5 \mathrm{~V}$ on the first oxidative cycle. Subsequent cycles show a redox couple centered at $1.75 \mathrm{~V}$, which cycles with good reversibility.

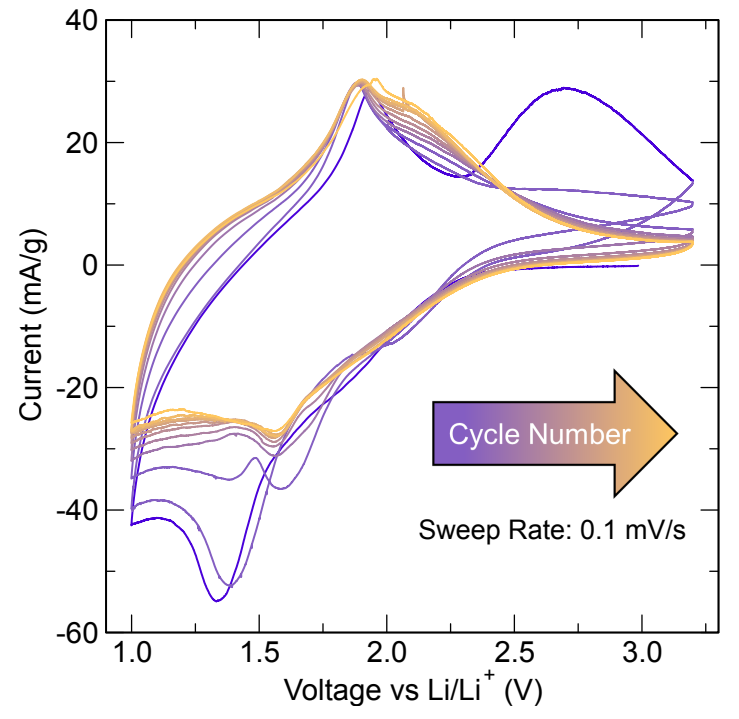

Figure S4: Cyclic voltammetry of $\mathrm{Nb}_{3} \mathrm{O}_{7} \mathrm{~F}$ with a voltage of $1.0-3.2 \mathrm{~V}$ demonstrates two initial oxidative peaks with a peak at $1.75 \mathrm{~V}$ and $2.5 \mathrm{~V}$. The peak at $2.5 \mathrm{~V}$ is lost after the first cycle while the redox couple at $1.75 \mathrm{~V}$ is maintained. 
Operando X-ray Diffraction Operando X-ray diffraction (XRD) measurements recorded diffracted intensity of both $\mathrm{NbO}_{2} \mathrm{~F}$ and $\mathrm{Nb}_{3} \mathrm{O}_{7} \mathrm{~F}$ throughout (de)lithiation in order to track structural changes. In order to better visualize subtle variations in intensity, heatmaps were generated in which a colored scale bar represents peak intensity while state of charge is plotted on the Y-axis. Heatmaps corresponding to Figure 5(a) and (b) are shown in S.I. Figures S5 and S7, respectively.

Upon the intercalation of 1.7 units of $\mathrm{Li}^{+}$, a triclinic phase is formed in $\mathrm{Nb}_{3} \mathrm{O}_{7} \mathrm{~F}$, as indexed in Figure S8. This phase is maintained during the discharge and initial charging until a delithiation of $x=1.9$.

As shown in Figure S9, a large loss of intensity is seen when $\mathrm{Nb}_{3} \mathrm{O}_{7} \mathrm{~F}$ is cycled with the displayed XRD patterns corresponding to the pristine material and the material at the end of a complete discharge/charge cycle.

Galvanostatic cycling of $\mathrm{NbO}_{2} \mathrm{~F}$ showed good reversibility when the lower voltage limit was limited to $1.5 \mathrm{~V}$, which avoids the formation of $\mathrm{Nb}^{3+}$. Operando XRD measurements show that the unit cell contracts and expands during the course of two complete cycles over the higher voltage window (Figure S6). In contrast, Figure 5(a) shows a large loss of diffracted intensity when $\mathrm{NbO}_{2} \mathrm{~F}$ is lithiated to $\mathrm{Li}_{2} \mathrm{NbO}_{2} \mathrm{~F}$.

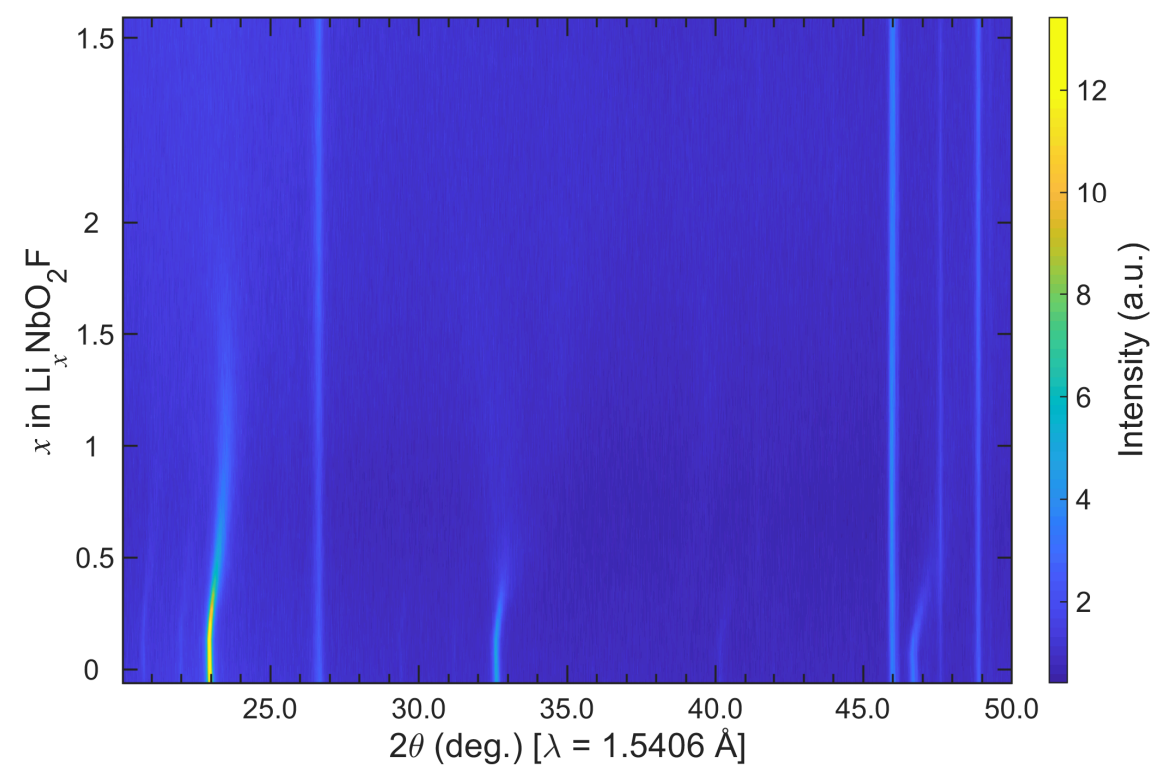

Figure S5: A heatmap of operando XRD for a complete cycle of $\mathrm{Li}_{x} \mathrm{NbO}_{2} \mathrm{~F}$ shows a loss of intensity on multiple peaks as long-range crystallinity is lost. 


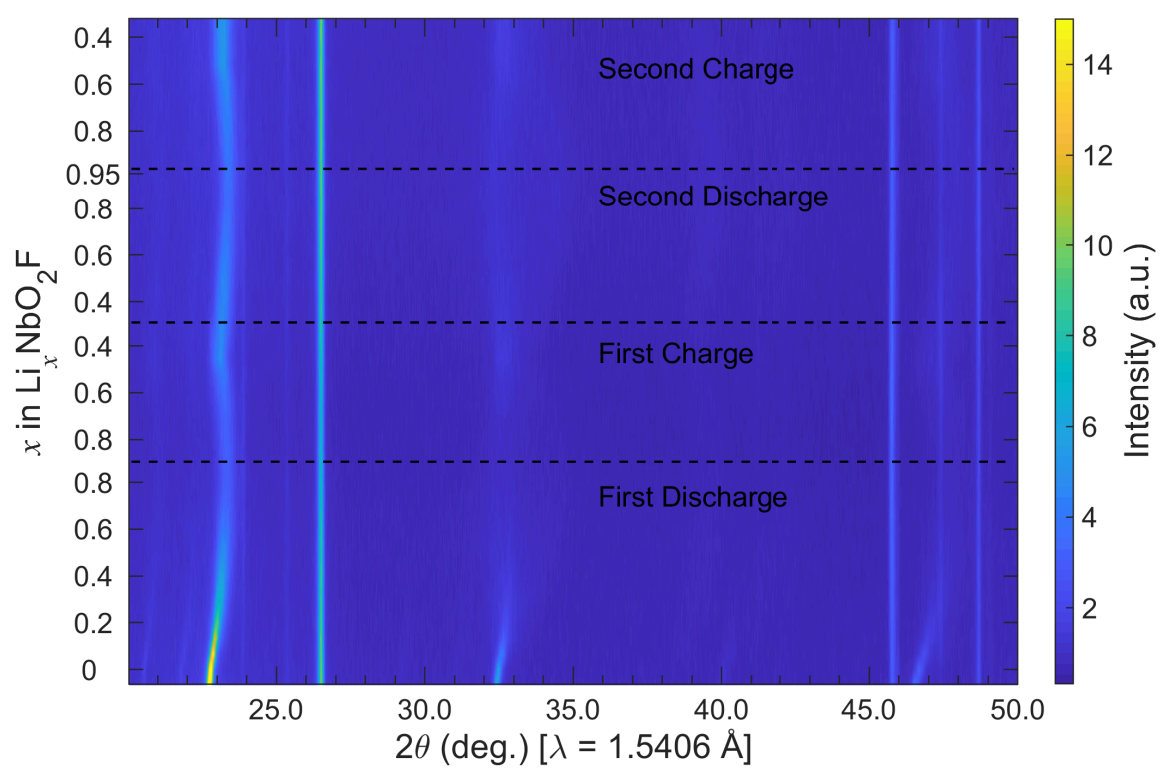

Figure S6: XRD patterns collected during two complete cycles of $\mathrm{NbO}_{2} \mathrm{~F}$ show that peaks shift upwards during discharge and downwards during charge showing the unit cell contracting and expanding. Peak intensity is maintained, showing that the crystallinity of the material is not lost.

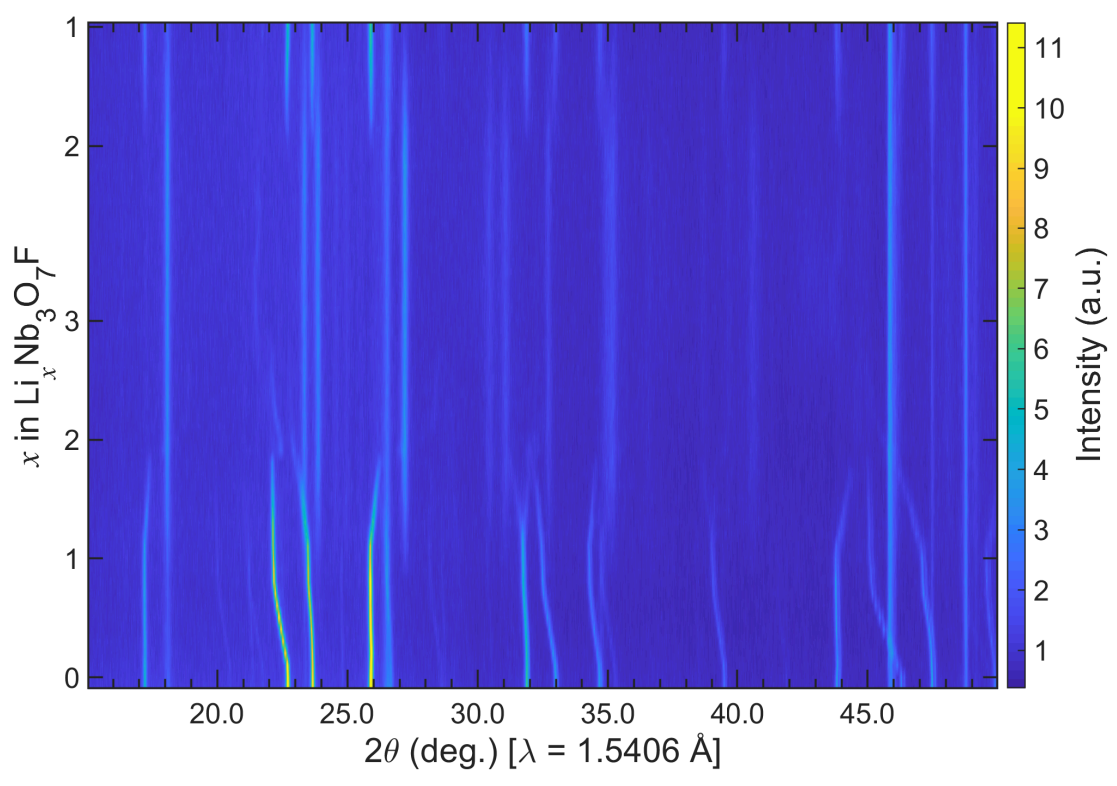

Figure S7: A heatmap of operando XRD for $\mathrm{Nb}_{3} \mathrm{O}_{7} \mathrm{~F}$ demonstrates the differences in behavior during discharge and charge. During discharge, a solid solution type process is observed with steady peak shift throughout lithiation. During charging, growth of $\mathrm{Nb}_{3} \mathrm{O}_{7} \mathrm{~F}$ is observed without the solid solution behavior seen on discharge. 


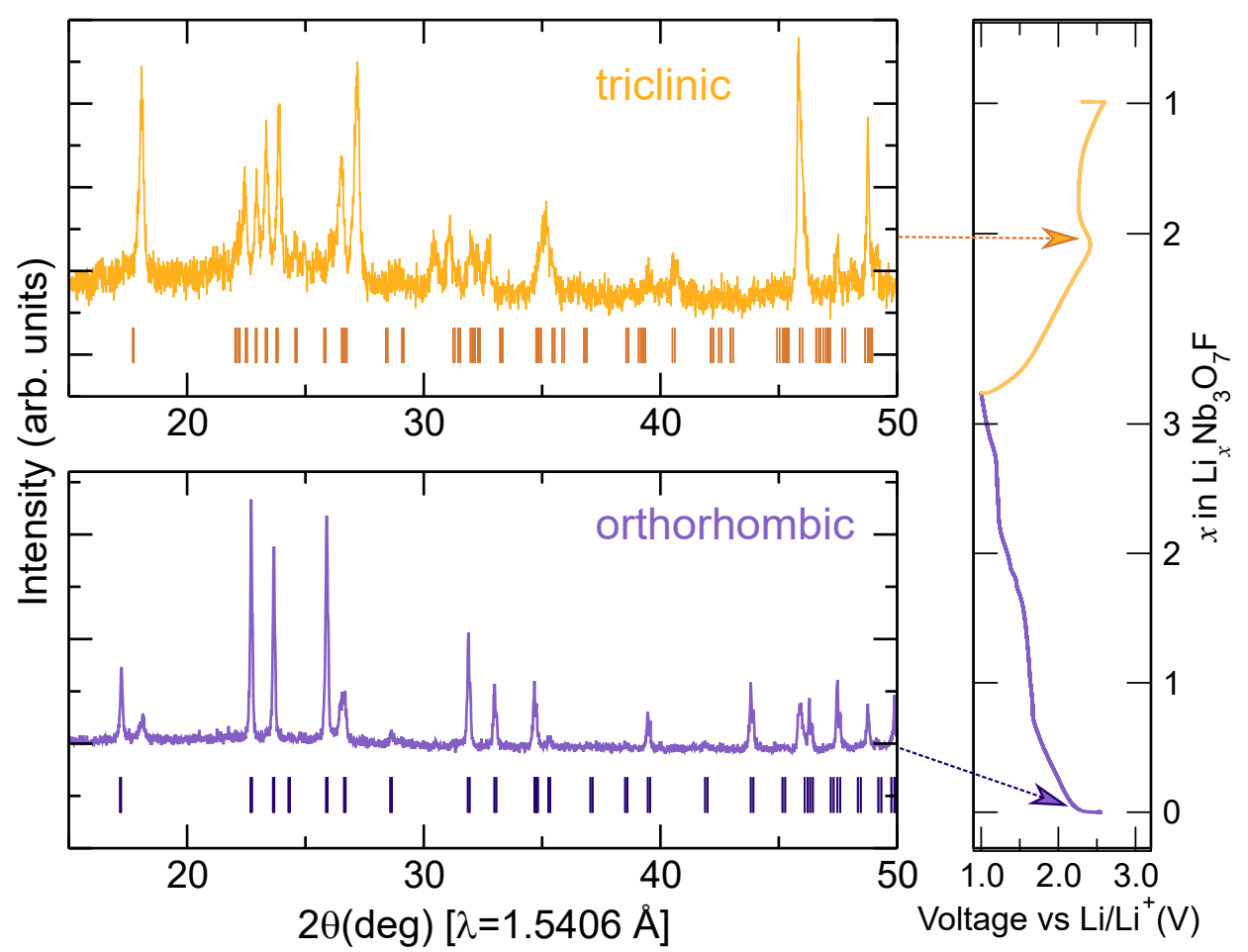

Figure S8: Indexed unit cells of selectively chosen operando scans show that prior to lithiation, $\mathrm{Nb}_{3} \mathrm{O}_{7} \mathrm{~F}$ is described well in orthorhombic space group Cmmm (bottom). During more complete lithiation $(x=1.7$ on discharge to $x=1.9$ on charge), the material adopts a triclinic phase (top) before returning to the original orthorhombic phase.

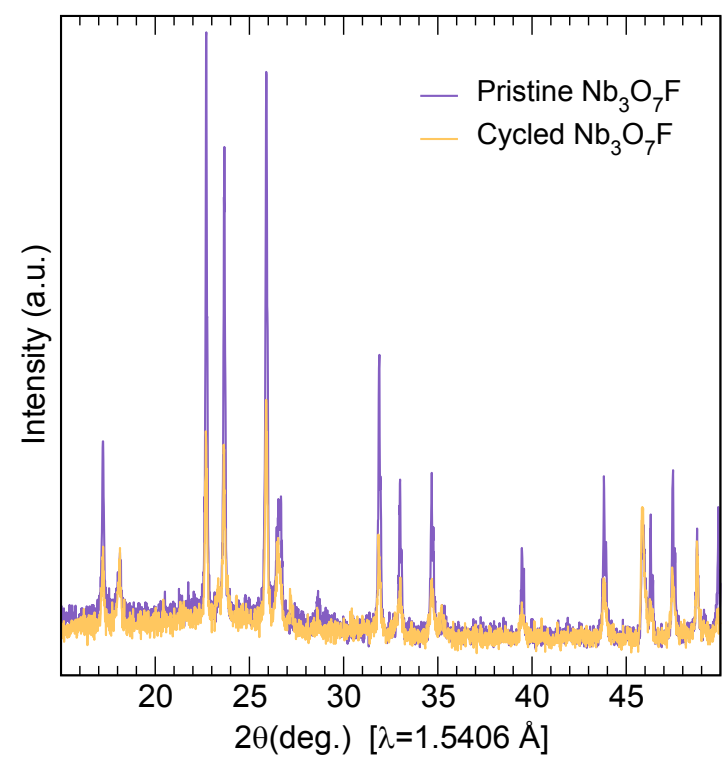

Figure S9: XRD patterns of pristine and cycled $\mathrm{Nb}_{3} \mathrm{O}_{7} \mathrm{~F}$ show that the original structure is recovered after the first cycle however a large degree of crystallinity is lost. Furthermore, relative peak intensities vary after cycling. 
X-ray Absorption Spectroscopy Operando Nb K-edge measurements were used to track the Nb oxidation state as well as local structural changes throughout the (de)lithiation process, as shown in Figures S10 and S11.

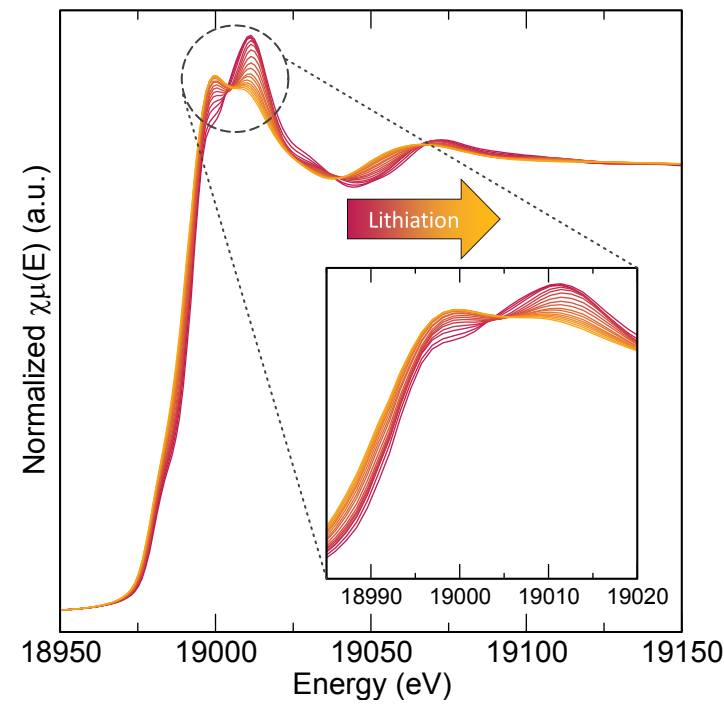

Figure S10: Nb K-edge X-ray absorption spectroscopy shows the characteristic down-shift of the K-edge associated with $\mathrm{Nb}$ reduction as $\mathrm{NbO}_{2} \mathrm{~F}$ is lithated.
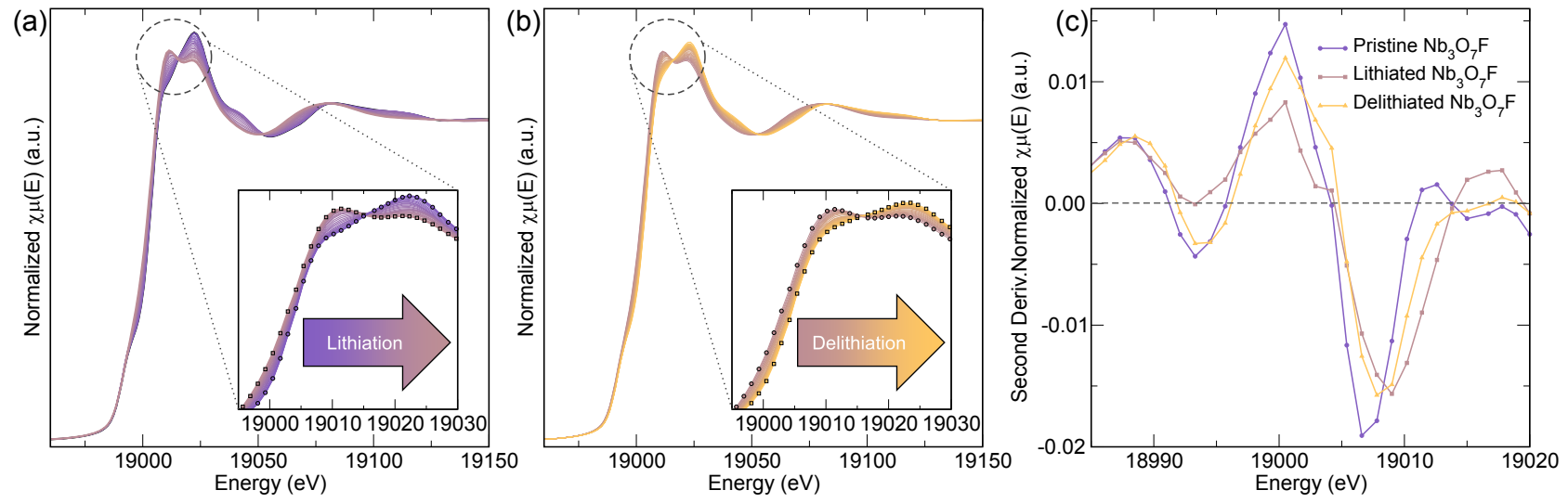

Figure S11: The XANES region of the $\mathrm{Nb} \mathrm{K}$-edge is seen to shift with redox in $\mathrm{Nb}_{3} \mathrm{O}_{7} \mathrm{~F}$. The discharge is demonstrated in (a) with an inset displaying the K-edge shift. The pristine material is indicated by circles, while the lithiated material is indicated by squares. The charge region is shown in (b) with circles and squares outlining patterns from the lithiated and delithiated samples respectively. The edge does not shift back completely upon charge, indicative of a partial recovery of the starting material. This is displayed in the second derivative plot in (c), which shows the failure of the delithiated sample to fully match the pristine sample. 
Raman Spectroscopy Additional raman spectra are provided to show a larger spectral range.

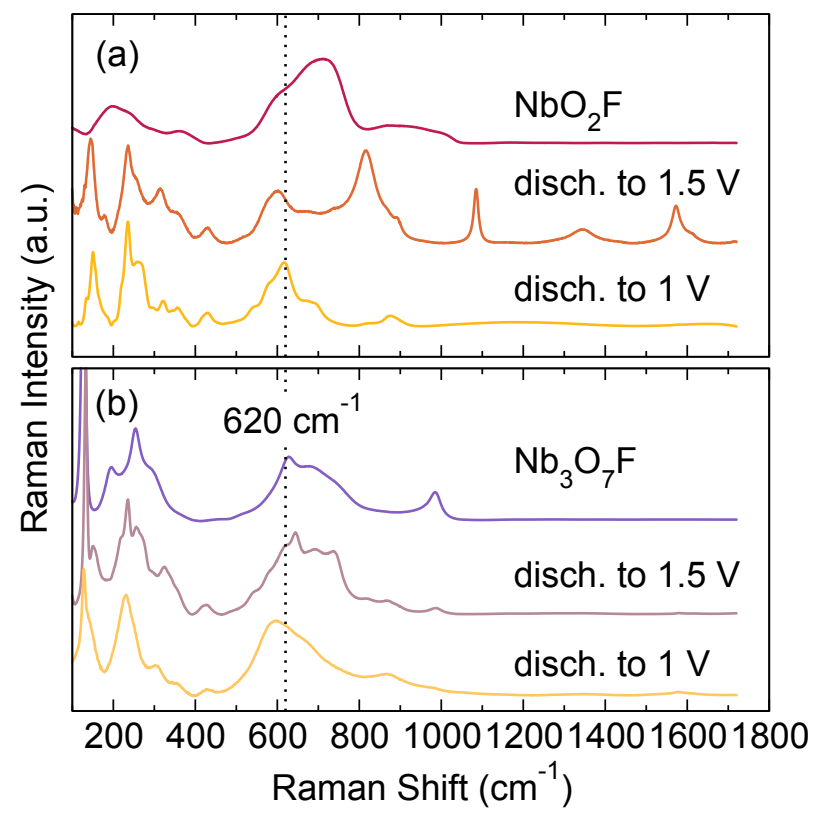

Figure S12: The full spectral range of all Raman spectra displayed in the main text.

\section{References}

(1) Ullah, H.; Guerin, K.; Bonnet, P. Synthesis of $\mathrm{Nb}_{2} \mathrm{O}_{5}$ Nanoplates and their Conversion into $\mathrm{NbO}_{2} \mathrm{~F}$ Nanoparticles by Controlled Fluorination with Molecular Fluorine. Eur. J. Inorg. Chem. 2019, 2019, 230-236.

(2) Zhu, H.; Zheng, Z.; Gao, X.; Huang, Y.; Yan, Z.; Zou, J.; Yin, H.; Zou, Q.; Kable, S. H.; Zhao, J.; Xi, Y.; Martens, W. N.; Frost, R. L. Structural Evolution in a Hydrothermal Reaction between $\mathrm{Nb}_{2} \mathrm{O}_{5}$ and $\mathrm{NaOH}$ Solution: From $\mathrm{Nb}_{2} \mathrm{O}_{5}$ Grains to Microporous $\mathrm{Na}_{2} \mathrm{Nb}_{2} \mathrm{O}_{6} \cdot 2 / 3 \mathrm{H}_{2} \mathrm{O}$ Fibers and $\mathrm{NaNbO}_{3}$ Cubes. J. Am. Chem. Soc. 2006, 128, 2373-2384.

(3) Barner, J. H. V.; Christensen, E.; Bjerrum, N. J.; Gilbert, B. Vibrational spectra of niobium(V) fluoro and oxo fluoro complexes formed in alkali-metal fluoride melts. Inorg. Chem. 1991, 30, 561-566.

(4) Gross, U.; Rüdiger, S.; Kemnitz, E.; Brzezinka, K.-W.; Mukhopadhyay, S.; Bailey, C.; Wander, A.; Harrison, N. Vibrational Analysis Study of Aluminum Trifluoride Phases. J. Phys. Chem. A 2007, 111, 5813-5819. 